\title{
Evaluation of Soxhlet extraction, accelerated solvent extraction and microwave-assisted extraction for the determination of polychlorinated biphenyls and polybrominated diphenyl ethers in soil and fish samples
}

\author{
Pu Wang, Qinghua Zhang*, Yawei Wang, Thanh Wang, Xiaomin Li, Lei Ding, Guibin Jiang \\ State Key Laboratory of Environmental Chemistry and Ecotoxicology, Research Center for Eco-Environmental Sciences, \\ Chinese Academy of Sciences, 18\# Shuangqing Road, Beijing 100085, China
}

\section{A R T I C L E I N F O}

Article history:

Received 2 December 2009

Received in revised form 18 January 2010

Accepted 18 January 2010

Available online 25 January 2010

\section{Keywords:}

Soxhlet extraction

Accelerated solvent extraction

Microwave-assisted extraction

Polychlorinated biphenyls

Polybrominated diphenyl ethers

\begin{abstract}
A B S T R A C T
Three commonly applied extraction techniques for persistent organic chemicals, Soxhlet extraction (SE), accelerated solvent extraction (ASE) and microwave-assisted extraction (MAE), were applied on soil and fish samples in order to evaluate their performances. For both PCBs and PBDEs, the two more recent developed techniques (ASE and MAE) were in general capable of producing comparable extraction results as the classical SE, and even higher extraction recoveries were obtained for some PCB congeners with large octanol-water partitioning coefficients $\left(K_{\mathrm{ow}}\right)$. This relatively uniform extraction results from ASE and MAE indicated that elevated temperature and pressure are favorable to the efficient extraction of PCBs from the solid matrices. For PBDEs, difference between the results from MAE and ASE (or SE) suggests that the MAE extraction condition needs to be carefully optimized according to the characteristics of the matrix and analyte to avoid degradation of higher brominated BDE congeners and improve the extraction yields.
\end{abstract}

(C) 2010 Elsevier B.V. All rights reserved.

\section{Introduction}

Polychlorinated biphenyls (PCBs) are industrial chemicals that have been used for more than half a century before a global ban was imposed in 2004. This group of contaminants has already been ubiquitously detected in the environment [1] and poses a threat to the health of animal and human [2,3]. Polybrominated diphenyl ethers (PBDEs), considered as emerging persistent organic pollutants (POPs), share similar chemical structure and environmental behavior with PCBs. They have been of increasing public concern in recent years since large quantities of these substances have been produced as additive flame retardants and might in turn be released into the environment and human body [4]. In order to study their environmental behaviors, it is imperative to develop sensitive and reliable analytical methods.

The conventional and classical method for extraction of PCBs and PBDEs from environmental samples is Soxhlet extraction (SE), which requires large amounts of solvent and more than $20 \mathrm{~h}$ to complete the extraction. As such, novel extraction techniques have been developed such as Soxtec, ultrasonic-assisted extraction (UAE), microwave-assisted extraction (MAE), supercritical fluid extraction

\footnotetext{
* Corresponding author. Tel.: +8610 62849818; fax: +86 1062849818 .

E-mail address: qhzhang@rcees.ac.cn (Q. Zhang).
}

(SFE) and accelerated solvent extraction (ASE), which significantly decreased the extraction time and solvent consumption, and nowadays frequently used for the extraction of POPs from various matrices $[5,6]$.

Analytical-scale MAE was firstly performed for the extraction of organic substances by Ganzler et al. [7] in 1986. It was considered as an appreciable technique superseding traditional SE. The main advantages are low temperature requirement, high extraction rate, automation and the possibility of simultaneously extracting different types of samples. MAE utilizes microwave energy to cause rotation of molecules with permanent dipole and disorganised movement, leading to rapid heating of the solvent and samples $[6,8]$. Pure alkanes cannot be used as solvents for the extraction of POPs from solid samples, and solvent mixtures with two different polarities such as $n$-hexane/acetone are often recommended. Many researches and applications of MAE have been carried out to extract organic pollutants from various matrices in recent years [9-18].

One of the latest contributions to the extraction techniques is ASE, which significantly streamlines sample preparation. Under elevated temperature and pressure, an extraction solvent can be used above its boiling point but still remains in the liquid state, increasing the kinetics of the extraction process. As a result, the extraction time and solvent consumption are significantly decreased. The first scientific publications on ASE appeared in $1995[19,20]$, and this technique has thereafter 
gained wide acceptance for the extraction of organic contaminants [17,18,21-25].

Several studies have been conducted to compare the extraction efficiencies of different techniques in regard to various organic compounds in recent years. However, only a few of them were performed using different techniques to simultaneously extract different analytes, such as organochlorine pesticides (OCPs) and PCBs [12], OCPs and polycyclic aromatic hydrocarbons (PAHs) [17], OCPs, PAHs and PCBs [15], PCBs and polychlorinated dibenzo-p-dioxins, dibenzofurans (PCDD/Fs) [24,25]. To our knowledge, only two previous studies focused on using different techniques to evaluate the extraction of both PCBs and PBDEs from biological matrices $[26,27]$. Furthermore, most of these studies were performed on spiked matrices or reference materials. As indicated by Abrha and Raghavan [28], contaminant recovery from spiked sample might not be comparable to the native matrix and only provides reliable benchmarks for further investigation. On the other hand, only few certificated reference materials (CRM) are available for PBDEs, which makes comparison of different extraction methods more difficult for this group of POPs.

This study aimed to investigate the extraction efficiencies of the classical SE and two "modern" techniques, MAE and ASE for the extraction of both PCBs and PBDEs from real soil and fish samples. The conditions have not been optimized individually for each extraction technique, but chosen from a comprehensive reference list which covers many of the most important articles published on PCBs and PBDEs extraction from various matrices [6,8,21-32].

\section{Materials and methods}

\subsection{Chemicals}

Acetone, $n$-hexane and dichloromethane (DCM) were purchased from Tedia Company Inc. (Fairfield, OH, USA) at pesticide grade and nonane was from Sigma (St. Louis, USA). Silica gel 60 $(0.063-0.100 \mathrm{~mm})$ was obtained from Merck, and basic alumina was from Aldrich. Anhydrous sodium sulfate $\left(\mathrm{Na}_{2} \mathrm{SO}_{4}\right)$, concentrated sulfuric acid $\left(\mathrm{H}_{2} \mathrm{SO}_{4}\right)$ and sodium hydroxide $(\mathrm{NaOH})$ were guaranteed reagent (purity $99.8 \%$ up) from domestic manufacturers. Prior to use, silica gel and anhydrous sodium sulfate were heated at $550^{\circ} \mathrm{C}$ for $12 \mathrm{~h}$ and $660^{\circ} \mathrm{C}$ for $6 \mathrm{~h}$, respectively. The preparation of acid silica gel and basic silica gel was described in our previous work [33]. In brief, acid silica gel was prepared from activated silica gel impregnated with $30 \%(w / w)$ concentrated $\mathrm{H}_{2} \mathrm{SO}_{4}$, and basic silica gel by activated silica gel impregnated with $1.2 \%(\mathrm{w} / \mathrm{w}) \mathrm{NaOH}\left(1 \mathrm{~mol} \mathrm{~L}^{-1}\right.$ solution). PBDEs standard mixture EO5103 was purchased from Cambridge Isotope Laboratories (Andover, MA). ${ }^{13} \mathrm{C}$-labeled surrogate standards of PCBs (EPA 68A-LCS) and PBDEs (BDE-LCS, ${ }^{13}$ C-BDE-47, $\left.-99,-153\right),{ }^{13}$ C-labeled injection standards of PCBs (EPA 68A-IS) were obtained from Wellington Laboratories (Guelph, Canada).

\subsection{Preparation of materials for method comparison}

Soil samples were obtained from electronic waste (E-waste) dismantling areas in the southeast of China, where contamination of heavy metals and POPs are very serious. The samples were freeze-dried and homogenized by sieving through a stainless steel 16-mesh sieve. Fish samples were obtained from a lake in the east suburb of Beijing, China, which receives large quantities of effluent wastewater from a municipal sewage treatment plant. The muscle was stripped, then freeze-dried and homogenized. All the samples were stored at $-20^{\circ} \mathrm{C}$ in a freezer until extraction.

\subsection{Extraction}

A mixture of $n$-hexane/acetone $(1: 1, \mathrm{v} / \mathrm{v})$ widely recommended and applied in many previous studies [6,8,11,16,21,23,24,28,31] was employed in this study to extract both PCBs and PBDEs from different matrices. Each extraction was carried out in three replicates for parallel test.

\subsection{1. $S E$}

The Soxhlet system was precleaned using $n$-hexane for $24 \mathrm{~h}$. About $3.0 \mathrm{~g}$ soil or $2.0 \mathrm{~g}$ fish were weighed and mixed with $8-10 \mathrm{~g}$ anhydrous sodium sulfate powder, then placed in the Soxhlet extraction thimble and extracted with $150 \mathrm{~mL} n$-hexane/acetone $(1: 1, v / v)$ for $24 \mathrm{~h}$. After extraction, the extracts were spiked with $10 \mu \mathrm{L} 68 \mathrm{~A}-\mathrm{LCS}$ and $10 \mu \mathrm{L}$ BDE-LCS, and then went through the clean-up procedure. One blank test (about $10.0 \mathrm{~g}$ anhydrous sodium sulfate powder) was processed with each batch of samples.

\subsubsection{ASE}

ASE was carried out on a Dionex ASE300 Accelerated Solvent Extractor (Dionex, USA). The stainless steel extraction cells were precleaned with $n$-hexane, and a piece of cellulose filter paper was thereafter placed on the bottom. Same amount of weighed samples as in SE procedure were mixed with 8-10 g anhydrous sodium sulfate powder and transferred to the extraction cells. The extraction conditions were based on US EPA method 3545 [29]: the solvent was $100 \mathrm{~mL} n$-hexane/acetone $(1: 1, \mathrm{v} / \mathrm{v})$, the temperature was $150^{\circ} \mathrm{C}$ and the pressure was $1500 \mathrm{psi}(10.3 \mathrm{MPa})$ with $7 \mathrm{~min}$ for heating, $8 \mathrm{~min}$ in the static state and 3 cycles for extraction. In the end, the extraction cell was flushed with solvent $(60 \%$ of the cell volume) and purged with nitrogen (120 s). The extracts were collected in $250 \mathrm{~mL}$ bottles with Teflon septa, then spiked with $10 \mu \mathrm{L}$ 68A-LCS and BDE-LCS and subjected to the clean-up procedure.

\subsection{3. $M A E$}

The MAE extraction was performed on a CEM MARS Xpress Microwave Accelerated Reaction System (CEM Corporation, Matthews, NC, USA). Before usage, the extraction cylinders were rinsed with $n$-hexane and extracted with pure acetone on MAE. As recommended in US EPA method 3546 [31], about $3.0 \mathrm{~g}$ soil or $2.0 \mathrm{~g}$ fish were weighed and mixed with $3-4 \mathrm{~g}$ anhydrous sodium sulfate powder, followed by loading into the extraction cylinders. $30 \mathrm{~mL} n$-hexane/acetone $(1: 1, \mathrm{v} / \mathrm{v})$ was added and the extraction was performed. The condition was as follows: the temperature was ramped to $115^{\circ} \mathrm{C}$ in $10 \mathrm{~min}$ and held for $15 \mathrm{~min}$, then cooled down in $20 \mathrm{~min}$; microwave power was $1200 \mathrm{~W}$. After extraction, the matrices and solvent were separated by centrifugation $(2000 \mathrm{rpm})$ for $5 \mathrm{~min}$, and then the solvent was decanted into a flat bottom flask. The extracts were spiked with exactly $10 \mu \mathrm{L} 68 \mathrm{~A}-\mathrm{LCS}$ and BDE-LCS and underwent the clean-up procedure.

\subsection{Clean-up procedure}

Sample clean-up procedure followed our previously established method with some modifications [33].

\subsubsection{Soil sample}

The extracts were evaporated on a vacuum rotary evaporator (Hedolph Co. model W. 2000, Germany). After solvent exchange with DCM and concentrated to $5 \mathrm{~mL}$, the extracts were fractioned using auto-gel permeation chromatography (GPC, AccuPrep ${ }^{\mathrm{TM}}, \mathrm{J}_{2}$ Scientific; Bio-Beads S-X3 with DCM as the mobile phase) to remove humic substance and sulfur. Subsequently, the collected fractions were solvent exchanged with $n$-hexane and eluted with $100 \mathrm{~mL}$ $n$-hexane through a multilayer silica gel column packed from the bottom up with $1 \mathrm{~g}$ silica gel, $4 \mathrm{~g}$ basic silica gel, $1 \mathrm{~g}$ silica gel, $8 \mathrm{~g}$ 
acid silica gel, $2 \mathrm{~g}$ silica gel and $2 \mathrm{~cm}$ anhydrous sodium sulfate. The column was pre-rinsed with $80 \mathrm{~mL} n$-hexane before the sample was loaded. After concentration, the eluate was transferred to a Kuderna-Danish (K-D) concentrator and evaporated to $0.2-0.3 \mathrm{~mL}$ under a stream of nitrogen flow. Finally, it was concentrated into $20 \mu \mathrm{L}$ nonane in GC vial with a liner (Agilent technologies, USA). Prior to instrumental analysis, the concentrate was spiked with $10 \mu \mathrm{L}$ 68A-IS to determine the recoveries of the ${ }^{13} \mathrm{C}$-labeled PCBs and PBDEs.

\subsubsection{Fish sample}

Different from the clean-up procedure for soil sample, the extracts of fish samples were firstly evaporated to dryness for determination of the lipid contents and then dissolved in $50 \mathrm{~mL}$ $n$-hexane. About $10 \mathrm{~g}$ acidic silica gel was added to remove the lipids. After being shaken for several minutes, the solution was filtered by a column packed with anhydrous sodium sulfate. The filtrate was concentrated and loaded to the multilayer silica gel column as described in the soil clean-up procedure. Then the eluate went through basic alumina column ( $6 \mathrm{~g}$ basic alumina, $1 \mathrm{~cm}$ anhydrous sodium sulfate from the bottom up) and eluted with $40 \mathrm{~mL} n$-hexane/DCM $(1: 1, \mathrm{v} / \mathrm{v})$. Thereafter, the eluate was concentrated, evaporated by nitrogen gas, and finally concentrated into $20 \mu \mathrm{L}$ nonane. As mentioned previously, $10 \mu \mathrm{L} 68 \mathrm{~A}-\mathrm{IS}$ was spiked into the solution before the instrumental analysis.

\subsection{Instrumental analysis}

Both PCBs and PBDEs were analyzed using high-resolution gas chromatography coupled with high-resolution mass spectrometry (HRGC/HRMS). The HRGC is an Agilent 6890N (Wilmington, USA) with a CTC PAL autosampler, and the HRMS is an AutoSpec Ultima (Waters Micromass, UK) with an electron impact (EI) ion source. The injection was operated in splitless mode with exactly $1 \mu \mathrm{L}$ solution and the GC columns were $60 \mathrm{~m}$ DB- 5 fused silica capillary column (J\&W, Scientific, $0.25 \mu \mathrm{m}$ film thickness, $0.25 \mathrm{~mm}$ i.d.) for PCBs and $30 \mathrm{~m}$ DB- 5 column $(0.10 \mu \mathrm{m}$ film thickness, $0.25 \mathrm{~mm}$ i.d.) for PBDEs, respectively. Helium was the carrier gas with a constant flow of $1.0 \mathrm{~mL} \mathrm{~min}^{-1}$. The temperature conditions of chromatographic analysis were described as follows: for PCBs: the initial column temperature was held at $80^{\circ} \mathrm{C}$ for $3 \mathrm{~min}$, then increased to $150^{\circ} \mathrm{C}$ at a rate of $15^{\circ} \mathrm{C} \mathrm{min}^{-1}$ and maintained for $2 \mathrm{~min}$, after increased to $270^{\circ} \mathrm{C}$ at $2.5^{\circ} \mathrm{C} \mathrm{min}^{-1}$ and held for $3 \mathrm{~min}$, it was heated to $330^{\circ} \mathrm{C}$ at $15^{\circ} \mathrm{C} \mathrm{min}^{-1}$ and then maintained for $13 \mathrm{~min}$; for PBDEs: the initial temperature was $90^{\circ} \mathrm{C}$ for $2 \mathrm{~min}$, then it was increased to $210^{\circ} \mathrm{C}$ at a rate of $25^{\circ} \mathrm{C} \mathrm{min}^{-1}$ and maintained for $1 \mathrm{~min}$, after that, it was elevated to $275^{\circ} \mathrm{C}$ at $10^{\circ} \mathrm{C} \mathrm{min}^{-1}$ and held for $10 \mathrm{~min}$, finally increased to $330^{\circ} \mathrm{C}$ at $25^{\circ} \mathrm{C} \mathrm{min}^{-1}$ and maintained for $10 \mathrm{~min}$. The HRMS was operated in VSIR mode at $R \geq 10,000$, the electron emission energy was set as $35 \mathrm{eV}$ and the source temperature was $270^{\circ} \mathrm{C}$ for PCBs and $280^{\circ} \mathrm{C}$ for PBDEs, respectively.

\section{Results and discussion}

As mentioned in previous studies [23,34], the Soxhlet extraction is generally considered as a reference method and benchmark for evaluation of many other extraction methods, which was also applied in this study.

The recoveries of ${ }^{13} \mathrm{C}$-labeled PCBs and PBDEs in the clean-up procedure ranged from $65 \%$ to $130 \%$ and $76 \%$ to $128 \%$, respectively, which are deemed acceptable according to US EPA methods 1668A [35] and 1614 (draft) [36]. The limits of detection (LOD) for PCBs and PBDEs were overall lower than $1.52 \mathrm{pg} \mathrm{g}^{-1}$ and $24.8 \mathrm{pg} \mathrm{g}^{-1}$, respectively. Even though they were lower for PCBs than for PBDEs in both of soil and fish samples, no significant difference $(p>0.05)$ was observed among the LOD values from three different extraction methods. Blank tests were also carried out for each method. CB-28 and $\mathrm{BDE}-47$ were the main contributors to laboratory background, CB-118, -138 and -153, BDE-28, -71 and -99 were also detected but at very low level, all of them merely corresponded to $<4 \%$ and $<9 \%$ of the concentrations of PCBs and PBDEs in the samples. The presented concentrations were therefore not blank corrected.

\subsection{Comparison of the results from the soil sample}

The concentrations of PCBs and PBDEs from SE, ASE and MAE are presented in Tables 1 and 2, and the recoveries normalized to the SE results are shown in Figs. 1 and 2, respectively. For PCBs, the ASE and MAE extraction generally yielded higher results compared to the SE extraction, with the normalized recovery ranges of $87-160 \%$ and $94-176 \%$, respectively. The highest recoveries were obtained for CB-180 and -153 , which have large octanol-water partitioning coefficients $\left(K_{\mathrm{ow}}\right)$ and present at significant concentrations in the samples. This indicated that the elevated temperature and pressure could significantly increase the yields of compounds with higher $K_{\mathrm{ow}}$ values. On the other hand, the results from MAE showed larger relative standard deviations (RSD) than that from ASE. This is different from the report of Sporring et al. [23], who

Table 1

The average concentrations of PCBs and the relative standard deviations (RSD) in the soil and fish samples $(n=3)$.

\begin{tabular}{|c|c|c|c|c|c|c|c|c|c|c|c|c|}
\hline \multirow[t]{2}{*}{ Compound } & \multicolumn{6}{|l|}{ Soil } & \multicolumn{6}{|l|}{ Fish } \\
\hline & Soxhlet $\left(\mathrm{pgg}^{-1}\right)$ & RSD (\%) & $\operatorname{ASE}\left(\mathrm{pg} \mathrm{g}^{-1}\right)$ & RSD (\%) & $\operatorname{MAE}\left(\mathrm{pg} \mathrm{g}^{-1}\right)$ & $\operatorname{RSD}(\%)$ & Soxhlet (pg g $\left.{ }^{-1}\right)$ & RSD (\%) & $\operatorname{ASE}\left(\mathrm{pg} \mathrm{g}^{-1}\right)$ & RSD (\%) & $\operatorname{MAE}\left(\mathrm{pgg}^{-1}\right)$ & $\operatorname{RSD}(\%)$ \\
\hline CB-28 & 8280 & 3.1 & 8690 & 1.6 & 8060 & 16 & 5510 & 4.8 & 5610 & 6.1 & 5640 & 11 \\
\hline CB-52 & 2220 & 2.1 & 2900 & 6.5 & 2910 & 20 & 980 & 5.5 & 954 & 7.4 & 848 & 17 \\
\hline CB-77 & 617 & 5.0 & 635 & 3.4 & 613 & 5.9 & 31.5 & 2.5 & 33.0 & 2.5 & 29.6 & 2.7 \\
\hline CB-81 & 63.2 & 14 & 66.3 & 1.2 & 60.2 & 9.5 & 5.36 & 7.4 & 5.97 & 1.5 & 4.90 & 8.0 \\
\hline CB-101 & 2080 & 5.8 & 2540 & 1.7 & 2530 & 21 & 605 & 5.4 & 579 & 16 & 588 & 6.2 \\
\hline CB-105 & 989 & 7.0 & 926 & 6.8 & 955 & 5.7 & 226 & 3.8 & 232 & 3.7 & 226 & 3.9 \\
\hline CB-114 & 103 & 19 & 139 & 4.3 & 111 & 15 & 21.8 & 3.2 & 22.2 & 4.2 & 21.0 & 5.1 \\
\hline CB-118 & 2120 & 1.2 & 2620 & 1.9 & 2700 & 21 & 503 & 3.3 & 514 & 2.4 & 492 & 5.4 \\
\hline CB-123 & 197 & 11 & 243 & 3.0 & 231 & 19 & 61.9 & 3.0 & 62.9 & 3.4 & 56.8 & 5.5 \\
\hline CB-126 & 28.7 & 9.1 & 30.2 & 4.4 & 30.5 & 8.0 & 5.27 & 1.2 & 5.49 & 0.9 & 5.25 & 5.6 \\
\hline CB-138 & 2310 & 8.6 & 2890 & 2.4 & 2850 & 17 & 613 & 4.0 & 529 & 17 & 597 & 5.5 \\
\hline CB-153 & 2080 & 11 & 3150 & 2.5 & 3240 & 11 & 610 & 3.0 & 547 & 17 & 582 & 5.8 \\
\hline CB-156 & 205 & 3.2 & 178 & 6.8 & 193 & 5.2 & 53.2 & 3.7 & 54.8 & 4.1 & 52.0 & 4.5 \\
\hline CB-157 & 50.2 & 4.1 & 48.2 & 5.6 & 50.1 & 4.2 & 13.1 & 6.4 & 14.3 & 2.7 & 13.3 & 3.1 \\
\hline CB-167 & 75.9 & 5.6 & 84.5 & 2.5 & 103 & 17 & 17.5 & 3.1 & 19.4 & 4.8 & 17.6 & 3.7 \\
\hline CB-169 & 2.77 & 15 & 2.90 & 16 & 2.60 & 21 & 0.61 & 12 & 0.67 & 12 & 0.68 & 2.5 \\
\hline CB-180 & 552 & 7.2 & 882 & 16 & 971 & 12 & 122 & 2.0 & 115 & 15 & 106 & 23 \\
\hline CB-189 & 6.70 & 16 & 7.27 & 13 & 7.20 & 20 & 3.62 & 8.2 & 3.90 & 4.8 & 3.83 & 7.3 \\
\hline CB-209 & 23.8 & 14 & 24.7 & 16 & 31.3 & 15 & 65.5 & 2.0 & 67.4 & 4.5 & 66.5 & 9.8 \\
\hline
\end{tabular}


Table 2

The average concentrations of PBDEs and the relative standard deviations (RSD) in the soil and fish samples $(n=3)$

\begin{tabular}{|c|c|c|c|c|c|c|c|c|c|c|c|c|}
\hline \multirow[t]{2}{*}{ Compound } & \multicolumn{6}{|l|}{ Soil } & \multicolumn{6}{|l|}{ Fish } \\
\hline & Soxhlet $\left(\mathrm{pgg}^{-1}\right)$ & RSD (\%) & $\operatorname{ASE}\left(\mathrm{pg} \mathrm{g}^{-1}\right)$ & RSD (\%) & MAE $\left(\mathrm{pgg}^{-1}\right)$ & RSD (\%) & Soxhlet $\left(\mathrm{pg} \mathrm{g}^{-1}\right)$ & RSD (\%) & $\operatorname{ASE}\left(\mathrm{pg} \mathrm{g}^{-1}\right)$ & RSD (\%) & $\operatorname{MAE}\left(\mathrm{pg} \mathrm{g}^{-1}\right)$ & RSD (\%) \\
\hline BDE-17 & 44.1 & 12 & 51.8 & 12 & 37.4 & 2.4 & 95.8 & 2.8 & 107 & 0.8 & 89.7 & 5.3 \\
\hline BDE-28 & 60.3 & 11 & 62.8 & 12 & 42.3 & 5.7 & 1700 & 1.0 & 1890 & 2.1 & 1590 & 9.4 \\
\hline BDE-47 & 215 & 4.7 & 209 & 0.7 & 206 & 16 & 8160 & 1.5 & 8190 & 2.0 & 6060 & 7.1 \\
\hline BDE-66 & 68.3 & 8.1 & 66.1 & 6.4 & 43.3 & 10 & 1180 & 2.9 & 988 & 4.1 & 1010 & 17 \\
\hline BDE-71 & 161 & 3.1 & 136 & 7.1 & 97.4 & 7.7 & 1190 & 3.2 & 1080 & 3.2 & 979 & 13 \\
\hline BDE-85 & 3.55 & 2.8 & 3.49 & 16 & 3.22 & 7.1 & 89.9 & 3.9 & 107 & 8.0 & 107 & 8.3 \\
\hline BDE-99 & 133 & 5.0 & 115 & 3.2 & 107 & 10 & 1720 & 1.8 & 1640 & 1.1 & 1330 & 3.5 \\
\hline BDE-100 & 32.9 & 4.6 & 29.7 & 2.4 & 26.3 & 9.0 & 304 & 0.6 & 233 & 2.3 & 304 & 16 \\
\hline BDE-138 & n.d. ${ }^{a}$ & - & n.d. & - & n.d. & - & 49.5 & 2.1 & 47.1 & 4.6 & 55.8 & 4.3 \\
\hline BDE-153 & 55.0 & 11 & 58.6 & 16 & 38.2 & 20 & 530 & 2.0 & 520 & 1.1 & 397 & 1.6 \\
\hline BDE-154 & 48.1 & 0.4 & 42.3 & 6.7 & 34.5 & 6.1 & 424 & 2.0 & 463 & 6.7 & 290 & 5.9 \\
\hline BDE-183 & 18.1 & 9.1 & 19.2 & 11 & 9.08 & 10 & 309 & 0.6 & 264 & 7.5 & 290 & 3.9 \\
\hline BDE-190 & n.d. & - & n.d. & - & n.d. & - & 35.3 & 10 & 34.7 & 17 & 34.1 & 9.1 \\
\hline
\end{tabular}

a n.d., not detected.

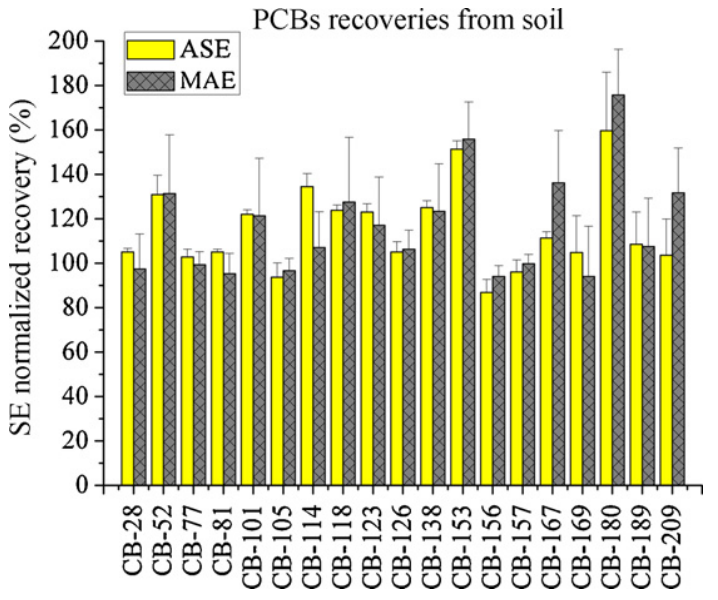

Fig. 1. The recoveries of individual PCB congeners in the soil sample for different techniques normalized to the Soxhlet method $(n=3)$.

indicated that MAE provided the overall lowest standard deviation (SD) values when comparing the extraction efficiencies of six different techniques for the determination of PCBs in soil. For PBDEs, ASE yielded comparable extraction results to SE, with normalized recoveries between $79 \%$ and $118 \%$. On the contrary, the results from MAE were generally low, with recovery range from $50 \%$ to $96 \%$. This

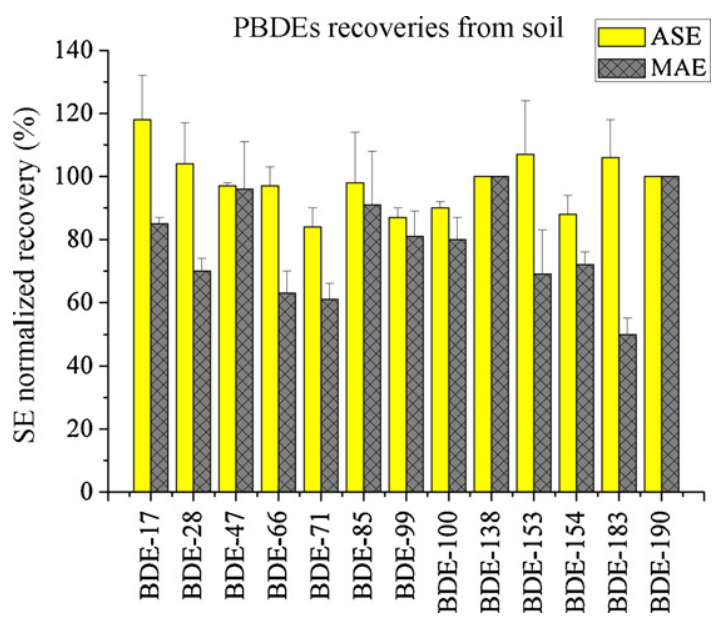

Fig. 2. The recoveries of individual PBDE congeners in the soil sample for different techniques normalized to the Soxhlet method $(n=3)$. BDE-138 and -190 were not detected in any samples, the recoveries were therefore considered as same as that of the SE extraction. is very similar to PBDEs extraction from marine biological tissues [13], of which the same temperature $\left(115^{\circ} \mathrm{C}\right)$ was utilized. However, Shin et al. [16] employed a mixture of $n$-hexane/acetone (3:1, $\mathrm{v} / \mathrm{v}$ ) and temperature of $130^{\circ} \mathrm{C}$ in the MAE extraction of PBDEs from the sewage sludge, and obtained a comparable result to SE. Furthermore, Vilaplana et al. [37] used isopropanol $/ n$-hexane as solvent in MAE at $130^{\circ} \mathrm{C}$ to extract brominated flame retardants (BFRs) from styrenic polymeric matrixes, and obtained almost complete recovery of tetrabromobisphenol A (TBBPA) and hexabromocyclododecane (HBCD), while deca-BDE was extracted at lower calculated concentration. Therefore, the relatively lower recovery of PBDEs in this study could be attributed to the unoptimized extraction conditions for the matrix.

\subsection{Comparison of the results from the fish sample}

The recoveries normalized to the SE results for PCBs and PBDEs in the fish samples are shown in Figs. 3 and 4, respectively. For PCBs, the ASE and MAE extraction presented the comparable recovery yields with the ranges of $86-111 \%$ and $87-112 \%$, respectively. Furthermore, the RSD values were relatively lower than in soil samples, which indicated that the extraction conditions are of great benefit to the analysis of PCBs in fish samples. For PBDEs, the recoveries from ASE and MAE were also in the same level with the ranges of $77-118 \%$ and $68-119 \%$, respectively. This is consistent with the report by Tapie et al. [26], who utilized different biological matrices to test the performance of ASE and MAE under different extraction conditions, and found that all the tested protocols were reliable and

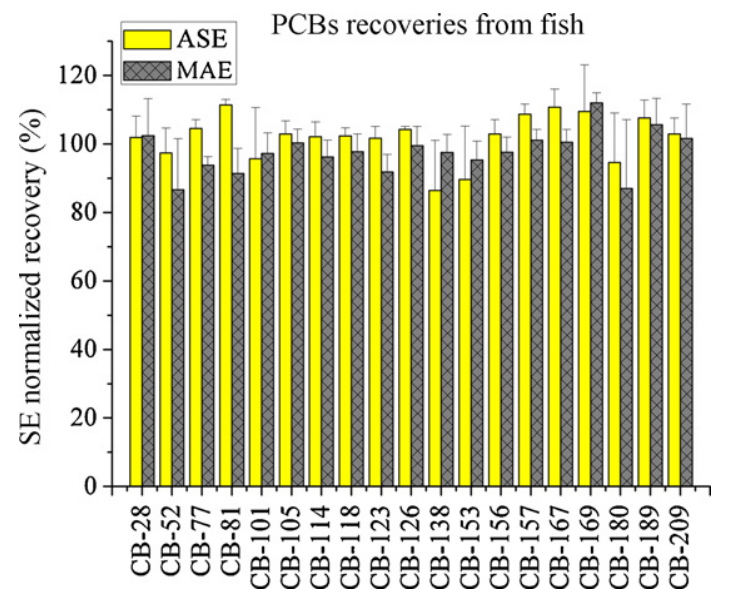

Fig. 3. The recoveries of individual PCB congeners in the fish sample for different techniques normalized to the Soxhlet method $(n=3)$. 


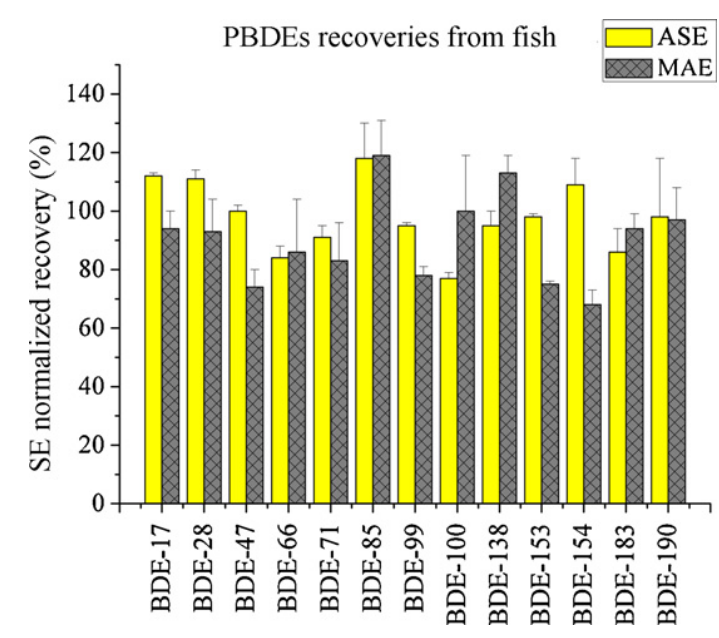

Fig. 4. The recoveries of individual PBDE congeners in the fish sample for different techniques normalized to the Soxhlet method $(n=3)$.

useful for PCBs and PBDEs analysis. Li et al. [38] also pointed out that MAE coupled with GC-EI-MS is an efficient and quantitative method for analyzing PBDEs in human adipose tissue compared to SE. However, ASE yielded relatively lower RSD values compared to MAE, which indicated that ASE could provide more robust and repeatable results under the specified extraction conditions in this study.

\subsection{Overall comparison of $P C B$ s and PBDEs results from different extraction techniques}

In general, both ASE and MAE could yield comparable results to SE for the extraction of PCBs in the soil and fish samples, even though high values were obtained for some congeners with higher $K_{\mathrm{ow}}$ values in soil. This indicates that elevated temperature and pressure are of great benefit to completely extract non-degradable congeners from the solid matrix compared to the traditional method.

For PBDEs, although commonly applied extraction conditions were employed, it seems that the specified conditions could lead to nonconformity of the extraction performance for different PBDE congeners and different matrices. Especially for MAE, generally low concentrations were obtained in soil samples.

Several factors could explain the variability of the results. Firstly, increasing temperature could increase solubility of analyte in the solvent, weaken the analyte-matrix interaction, and increase the vapor pressure of the analyte [28]. However, higher brominated BDE congeners are sensitive to thermal degradation compared to PCBs, which therefore requires suitable temperature and other related conditions to do the extraction. Secondly, the characteristics of the matrices are different; soil contains high organic carbon and fish has high lipid content, which affects the adsorption behavior of the analytes. As indicated by Abrha and Raghavan [28], PCBs extraction is sensitive to carbon content and matrix structure, as well as the type of compound in the matrix. Besides, reduced particle size of the matrix could enhance the extraction yield, attributable to a higher swelling effect of the solvent and favorable desorption of the analytes from the matrix [37]. On the other hand, comparison of different solvent mixtures applied in lipid extraction from biological organ tissues demonstrated that DCM/acetone and $n$-hexane/acetone systems produced better extraction efficiency than other solvent combinations [39], suggesting that the extraction conditions should be optimized according to the matrix and analyte. With regard to different methodological approaches, it was noteworthy that different pressures (ASE: $1500 \mathrm{psi}$; MAE: $\leq 200 \mathrm{psi}$ ), extraction times (SE: $\geq 24 \mathrm{~h}$; ASE: $\sim 40 \mathrm{~min}$; MAE: $\sim 30 \mathrm{~min}$ ) and different extract-collection steps after extraction (ASE, SE: both are continuous; MAE: discontinuous, requires filtration after extraction) are required, which could also cause the variation of results [18].

\section{Conclusion}

In summary, ASE and MAE, both temperature/pressureenhanced extraction techniques, could provide comparable or even better results than the SE extraction for extracting both PCBs and PBDEs from soil and fish samples, and showed a significant advantage of reducing extraction time and solvent consumption. It is noteworthy that, for PBDEs, the extraction conditions with high temperature need careful optimization on different matrices to avoid degradation of higher brominated congeners and obtain optimum extraction efficiency.

\section{Acknowledgements}

This work is financially supported by the National Natural Science Foundation of China (20777079 and 20621703), the National Hi-tech Research and Development Program of China (2007AA061601 and 2007AA061602) and the National Basic Research Program of China (2009CB421600).

\section{References}

[1] I.C.T. Nisbet, A.F. Sarofim, Environ. Health Perspect. 1 (1972) 21-38.

[2] M. Luotamo, J. Järvisalo, A. Aitio, Environ. Health Perspect. 60 (1985) 327332.

[3] S.H. Safe, Crit. Rev. Toxicol. 24 (1994) 87-149.

[4] A. Sjödin, D.G. Patterson Jr., Å. Bergman, Environ. Sci. Technol. 35 (2001) 3830-3833.

[5] E. Eljarrat, D. Barceló, Trends Anal. Chem. 23 (2004) 727-736.

[6] N. Fidalgo-Used, E. Blanco-Gonzalez, A. Sanz-Medel, Anal. Chim. Acta 590 (2007) 1-16.

[7] K. Ganzler, A. Salgo, K. Valko, J. Chromatogr. 371 (1986) 299-300.

[8] C.S. Eskilsson, E. Björklund, J. Chromatogr. A 902 (2000) 227-250.

[9] V. Lopez-Avila, R. Young, J. Benedicto, P. Ho, R. Kim, Anal. Chem. 67 (1995) 2096-2102.

[10] V. Lopez-Avila, J. Benedicto, C. Charan, R. Young, W.F. Beckert, Environ. Sci. Technol. 29 (1995) 2709-2712.

[11] S. Jayaraman, R.J. Pruell, R. McKinney, Chemosphere 44 (2001) 181-191.

[12] D. Martens, M. Gfrerer, T. Wenzl, A. Zhang, B.M. Gawlik, K.W. Schramm, E. Lankmayr, A. Kettrup, Anal. Bioanal. Chem. 372 (2002) 562-568.

[13] S. Bayen, H.K. Lee, J.P. Obbard, J. Chromatogr. A 1035 (2004) 291-294.

[14] P. Sanz, B. Fabrellas, Organohalogen Compd. 66 (2004) 86-93.

[15] V. Yusà, A. Pastor, M. De la Guardia, Anal. Chim. Acta 540 (2005) 355-366.

[16] M. Shin, M.L. Svoboda, P. Falletta, Anal. Bioanal. Chem. 387 (2007) 29232929.

[17] W. Wang, B. Meng, X. Lu, Y. Liu, S. Tao, Anal. Chim. Acta 602 (2007) 211-222

[18] N. Itoh, M. Numata, Y. Aoyagi, T. Yarita, Anal. Chim. Acta 612 (2008) 44-52.

[19] B.E. Richter, J.L. Ezzell, D. Felix, K.A. Roberts, D.W. Later, Am. Lab. 27 (1995) 24-28.

[20] J.L. Ezzell, B.E. Richter, W.D. Felix, S.R. Black, J.E. Meikle, LC-GC (Mag. Sep. Sci.) 13 (1995) 390-399.

[21] E. Björklund, S. Bøwadt, T. Nilsson, L. Mathiasson, J. Chromatogr. A 836 (1999) 285-293.

[22] S. Sporring, E. Björklund, J. Chromatogr. A 1040 (2004) 155-161.

[23] S. Sporring, S. Bøwadt, B. Svensmark, E. Björklund, J. Chromatogr. A 1090 (2005) $1-9$.

[24] O. Kiguchi, T. Kobayashi, K. Saitoh, N. Ogawa, J. Chromatogr. A 1108 (2006) $176-182$.

[25] K. Wiberg, S. Sporring, P. Haglund, E. Björklund, J. Chromatogr. A 1138 (2007) 55-64.

[26] N. Tapie, H. Budzinski, K. Le Ménach, Anal. Bioanal. Chem. 391 (2008) 2169-2177.

[27] J.M. Keller, R.F. Swarthout, B.K. Carlson, J. Yordy, A. Guichard, M.M. Schantz, J.R. Kucklick, Anal. Bioanal. Chem. 393 (2009) 747-760.

[28] Y. Abrha, D. Raghavan, J. Hazard. Mater. B80 (2000) 147-157.

[29] U.S. EPA Method 3545, Pressurized Fluid Extraction. EPA SW-846, U.S. Government Printing Office, Washington, DC, 1995.

[30] Application Note 352: Rapid Determination of Persistent Organic Pollutants (POPs) Using Accelerated Solvent Extraction (ASE®), Dionex, Sunnyvale, CA, 1999. 
[31] U.S. EPA Method 3546, Microwave Extraction. EPA SW-846, U.S. Government Printing Office, Washington, DC, 1999.

[32] J.M.R. Bélanger, J.R.J. Paré, Anal. Bioanal. Chem. 386 (2006) 1049-1058.

[33] H.X. Liu, Q.H. Zhang, Z.W. Cai, A. Li, Y.W. Wang, G.B. Jiang, Anal. Chim. Acta 557 (2006) 314-320.

[34] M. Gfrerer, S. Chen, E.P. Lankmayr, X. Quan, F.L. Yang, Anal. Bioanal. Chem. 378 (2004) 1861-1867.

[35] EPA Method 1668, Revision A: Chlorinated Biphenyl Congeners in Water, Soil, Sediment and Tissue by HRGC/HRMS, United States Environmental Protection Agency, Office of Science and Technology, Washington, DC, 1999.
[36] EPA Method 1614 (Draft): Brominated Biphenyl Ethers in Water, Soil, Sediment and Tissue by HRGC/HRMS, United States Environmental Protection Agency, Office of Science and Technology, Washington, DC, 2003.

[37] F. Vilaplana, P. Karlsson, A. Ribes-Greus, P. Ivarsson, S. Karlsson, J. Chromatogr. A 1196-1197 (2008) 139-146.

[38] Q.Q. Li, A. Loganath, Y.S. Chong, J.P. Obbard, J. Chromatogr. B 819 (2005) 253-257.

[39] K. Saito, A. Sjodin, C.D. Sandau, M.D. Davis, H. Nakazawa, Y. Matsuki, D.G. Patterson Jr., Chemosphere 57 (2004) 373-381. 